\title{
Tables, Figures, and Maps
}

\section{TABLES}

1.1 Comparative Vocabulary of European Languages 10

1.2 Comparative Vocabulary of the Romance Languages 18

2.1 Grimm's Law 44

5.1 Early Identification of Papuan Groups 175

5.2 Recent Identification of Papuan Groups 179

6.1 Amerind Languages with More Than 100,000 Speakers 204

6.2 Initial Identification of New World Families 228

7.1 A Possible Global Etymology (Greenberg 1976) 261

8.1 Pejorative Language Names 278

8.2 Overview of Language Phyla 286

\section{FIGURES}

1.1 Examples of Subgroupings 5

1.2 A Typical Subgrouping 5

1.3 A Possible Alternative Subgrouping 5

1.4 A Proposed Subgrouping of French and Italian Dialects 7

1.5 Dialects That May Be Represented as a Single Language 8

1.6 Dialects That May Be Represented as Multiple Languages 8

1.7 A Possible Subgrouping of Family A 15

1.8 Differentiation of the Indo-European Family (Partial) 16

1.9 Differentiation of the Romance Family (Partial) 17

4.1 Subgrouping of Southeast Asian Families, 1900 and $1980 \quad 150$

4.2 Different Definitions of Austric 154

8.1 Branching-Tree Diagram of Family X 281 
MAPS

2.1 The Indo-Hittite Family 36

2.2 The Uralic-Yukaghir Family 64

2.3 The Caucasian Family 71

3.1 The Afro-Asiatic Family 86

3.2 The Niger-Kordofanian Family 96

3.3 The Nilo-Saharan Family 108

3.4 The Khoisan Family 115

4.1 The Altaic Family 127

4.2 The Chukchi-Kamchatkan Family 135

4.3 The Dravidian Family 137

4.4 The Sino-Tibetan Family 142

4.5 The Miao-Yao, Austroasiatic, and Daic Families 149

5.1 The Austronesian Family 160

5.2 The Indo-Pacific Family 173

5.3 The Australian Family 185

6.1 The Eskimo-Aleut Family 194

6.2 The Na-Dene Family 196

6.3 The Amerind Family 201

6.4 The Amerind Family, North and Central America 202

6.5 The Amerind Family, South America 203

8.1 The World's Language Families 284 